\title{
PERFIL DAS COOPERATIVAS DE CRÉDITO MÚTUO DO ESTADO DE MINAS GERAIS
}

\author{
Valéria Gama Fully Bressan ${ }^{1}$ \\ Marcelo José Braga ${ }^{2}$
}

\begin{abstract}
Resumo - Dada a relevância das cooperativas de crédito em níveis mundial e nacional, o objetivo deste trabalho foi descrever o perfil das cooperativas de economia e crédito mútuo do Estado de Minas Gerais. O levantamento dos dados deu-se no período de maio a junho de 2004 , e a amostra contemplou $18,85 \%$ da população. As principais constatações foram: essas cooperativas possuem, em média, 16 anos de existência; $92 \%$ dos associados que solicitaram empréstimos foram atendidos; o nível de inadimplência foi de 22,34\%; cooperativas com maior tempo de existência praticavam taxas de juros menores; e a maior parte dos gestores tem percepção adequada do real significado de uma cooperativa e concorda com o princípio da livre adesão nas cooperativas de crédito. De modo geral, essas cooperativas de crédito oferecem serviços com custos menores que os da média do sistema bancário, cumprindo, assim, seu papel no atendimento às necessidades financeiras de seus cooperados.
\end{abstract}

Palavras-chave: cooperativas de crédito mútuo, microfinanças, Minas Gerais.

\section{Introdução}

As cooperativas de crédito são organizações que prestam serviços financeiros aos associados, razão pela qual são instituições importantes para o desenvolvimento de muitos países. Na Alemanha, essas cooperativas possuem cerca de 15 milhões de associados, que correspondem a cerca de $20 \%$ de todo o movimento financeiro e bancário desse país. Na Holanda, o Rabobank atende a mais de $90 \%$ das demandas rurais, e, nos EUA, há 12 mil unidades de atendimento cooperativo apenas no sistema Credit Union National Association (CUNA), que reúne cooperativas de crédito do tipo desjardins. Além dessas, os bancos

Doutoranda em Economia Aplicada pela Universidade Federal de Viçosa. E-mail: valeria.fully@ gmail.com

Professor Adjunto do Departamento de Economia Rural da Universidade Federal de Viçosa.

E-mail:mjbraga@ufv.br 
cooperativos respondem por mais de um terço dos financiamentos agrícolas dos Estados Unidos e estima-se que 25\% dos norte-americanos sejam associados a uma cooperativa de crédito (Meinen, 2002, citado por Pinheiro, 2005). Nesse mesmo trabalho, Pinheiro (2005) mencionou que, em 2000, 46\% do total das instituições de crédito na Europa eram cooperativas e estas respondiam por aproximadamente $15 \%$ do volume de intermediação financeira.

No Brasil, as cooperativas de crédito registraram expressiva expansão na última década. De 1993 a 2004, enquanto o número de instituições financeiras do País caiu quase à metade, ao diminuir de 1.065 para 646, as cooperativas de crédito aumentaram de 877 para 1.436. A participação das cooperativas de crédito na área bancária do Sistema Financeiro Nacional ainda é pequena, mas o seu crescimento é significativo tanto no que diz respeito às operações de crédito quanto ao patrimônio líquido. Em 1995, as cooperativas de crédito detinham uma fatia de apenas $0,44 \%$ das operações de crédito, participação que avançou para 2,3\% em 2005. A evolução do patrimônio líquido também é expressiva em igual comparativo: de 1,44\% para 2,56\% (Pinheiro, 2005).

De acordo com o World Council of Credit - WOCCU (2005), em dezembro de 2004 havia cerca de 136 milhões de membros de cooperativas de crédito distribuídos em 91 países. No mesmo período, no Brasil, as cooperativas de crédito possuíam mais de dois milhões de cooperados (Pinheiro, 2005). Nesse contexto, estas desempenham importante papel, uma vez que a maioria das pessoas em países em desenvolvimento não possui acesso a serviços financeiros formais, conforme verificado por Parente (2003), ao afirmar que 30\% dos 5.636 municípios brasileiros não possuem agência financeira e $70 \%$ da população não tem conta bancária.

Não há no Brasil uma entidade de cúpula única para o cooperativismo de crédito, sendo este organizado em três grandes sistemas principais: SICOOB (Sistema de Cooperativas de Crédito do Brasil), SICREDI (Sistema de Crédito Cooperativo) e UNICRED (Confederação Nacional das Cooperativas Centrais Unicred). O SICREDI é composto pela 
confederação (confederação interestadual das cooperativas ligadas ao SICREDI), pelo SICREDI Serviços, pelo BANSICREDI ${ }^{3}$ (Banco Cooperativo SICREDI S.A.), por cinco centrais e 142 singulares, estando presente em oito Estados da Federação (Pinheiro, 2005). De acordo com dados da Organização das Cooperativas Brasileiras -OCB (2006), existem 1.102 cooperativas de crédito no Brasil, sendo 253 situadas no Estado de Minas Gerais.

Dada a relevância do cooperativismo de crédito tanto em nível mundial quanto nacional, pode-se notar que vários autores (Junqueira, 2003; Schröder, 2005; Fully-Bressan, 2002; Quiroga et al., 2004; Gonçalves, 2006) realizaram trabalhos que abordavam a temática das cooperativas de crédito. Entretanto, de modo geral, não tiveram preocupação de apresentar o perfil das cooperativas de crédito.

Com o intuito de buscar informações que pudessem traçar o perfil das cooperativas de crédito mútuo, especificamente de Minas Gerais, podese constatar, por meio de levantamento junto à diretoria dessas cooperativas, o interesse desta em conhecer o perfil de seus pares, sendo essa a primeira motivação para a realização desta pesquisa. Corrobora a justificativa deste trabalho a afirmação de Pinheiro (2005), que relatou que, "apesar do potencial de crescimento do segmento no Brasil e da importância que vem adquirindo, é grande o desconhecimento sobre cooperativismo de crédito no Brasil, tanto por parte do público em geral, quanto mesmo por parte de conceituados autores".

Tem-se clara a limitação de se traçar um perfil, em nível nacional e simultaneamente, de ambos os ramos do cooperativismo de crédito (crédito mútuo e crédito rural), razão por que se buscou avaliar, nesta etapa do trabalho, as cooperativas de crédito mútuo no Estado de Minas Gerais.

Banco comercial formado com capital das cooperativas de crédito singulares e respectivas centrais, sob a forma de sociedade anônima. 
O presente trabalho teve por objetivo descrever o perfil das cooperativas de economia e crédito mútuo de Minas Gerais. A próxima seção apresenta a metodologia que aborda a amostragem e a coleta de dados. Subseqüentemente é apresentada a discussão dos resultados, que foi dividida em: a) caracterização das cooperativas de crédito mútuo do Estado de Minas Gerais; b) serviços e taxas cobradas aos associados por essas cooperativas de crédito mútuo; c) análise das cooperativas na concessão de crédito; e d) o ponto de vista dos gestores em relação às cooperativas de crédito. Por fim, são apresentadas as conclusões.

\section{Metodologia}

\subsection{Amostragem e coleta de dados}

No período de coleta de dados, entre maio e junho de 2004, a população das cooperativas de crédito mútuo do Estado de Minas Gerais (CECMMG) era de 122 unidades. Foram enviados questionários para todas as cooperativas, e, destes, obteve-se o retorno de 23 , ou seja, a amostra obtida representa $18,85 \%$ da população.

Trata-se de uma pesquisa cuja amostragem é conduzida, sem reposição, a partir de uma população finita de 122 cooperativas. Nesse caso, conforme Levine et al. (2000, p. 274), em particular quando o tamanho da amostra $n$ não é pequeno, em comparação com o tamanho da população $\mathrm{N}$ ( "isto é, mais de $5 \%$ da população é utilizada como amostra"), de modo que $n / N>0,05$, um fator de correção para a população finita (cpf) deveria ser utilizado na definição tanto do erro-padrão da média aritmética quanto do erro-padrão da proporção. $\mathrm{O}$ fator de correção para população finita é expresso por: $c p f=\sqrt{\frac{N-n}{N-1}}$, em que $N$ é o tamanho da população e $n$ o tamanho da amostra. 
Para algumas questões, no cálculo do erro de amostragem considerouse a média aritmética e, para outras, a proporção, dada a característica de cada pergunta do questionário aplicado. Dessa forma, têm-se as seguintes fórmulas para cálculo do erro de amostragem, considerando o nível de confiança de $90 \%(Z=1,645)$ :

- Erro de amostragem para lidar com médias aritméticas $e_{m}=Z * \frac{\sigma}{\sqrt{n}} * \sqrt{\frac{N-n}{N-1}} ; \mathrm{e}$

- Erro de amostragem para lidar com proporções $\mathrm{e}_{\mathrm{p}}=\mathrm{Z} * \sqrt{\frac{\mathrm{p}(1-\mathrm{p})}{\mathrm{n}}} * \sqrt{\frac{\mathrm{N}-\mathrm{n}}{\mathrm{N}-1}}$, em que:

- Erro-padrão para a média aritmética $=\frac{\sigma}{\sqrt{n}}$, sendo $\sigma=$ desvio-padrão.

- Erro-padrão para a proporção $=\sqrt{\frac{p(1-p)}{n}}$, sendo $\mathrm{p}=$ a proporção em que o fenômeno estudado se verifica e (1-p), a proporção complementar.

O questionário aplicado abordou questões, fechadas e abertas, referentes a descrição das CECM-MG, estrutura de funcionamento, tipos de empréstimos, financiamentos e serviços oferecidos, assim como taxas cobradas, demanda de serviços por parte dos cooperados, opinião dos gestores sobre a livre adesão nas cooperativas de crédito e sua compreensão sobre o significado de uma empresa cooperativa. 
De acordo com Gil (1999), o questionário apresenta as seguintes vantagens: a) possibilita atingir grande número de pessoas, mesmo que estejam dispersas numa área geográfica muito extensa, já que o questionário pode ser enviado pelo correio; b) implica menores gastos com pessoal, posto que o questionário não exige o treinamento dos pesquisadores; c) garante o anonimato das respostas; d) permite que as pessoas o respondam no momento em que julgarem mais conveniente; e e) não expõe os pesquisadores à influência das opiniões e do aspecto pessoal do entrevistado. Por outro lado, esse mesmo autor mostra as seguintes limitações para o questionário: a) exclui as pessoas que não sabem ler e escrever, o que, em certas circunstâncias, conduz a graves deformações nos resultados da investigação; b) impede o auxílio ao informante quando este não entende corretamente as instruções ou perguntas; c) impede o conhecimento das circunstâncias em que foi respondido, o que pode ser importante na avaliação da qualidade das respostas; d) não oferece a garantia de que a maioria das pessoas o devolva devidamente preenchido, o que pode implicar a significativa diminuição da representatividade da amostra; e) envolve, geralmente, número relativamente pequeno de perguntas, porque é sabido que questionários muito extensos apresentam alta probabilidade de não serem respondidos; ef) apresenta resultados proporcionais bastante críticos em relação à objetividade, pois os itens podem ter significados diferentes para cada sujeito pesquisado.

\section{Resultados e discussão}

\subsection{Caracterização das cooperativas de crédito mútuo do Estado de Minas Gerais}

As cooperativas de crédito mútuo de Minas Gerais (CECM-MG) possuem, em média, 16 anos; destas, $43 \%$ têm postos de atendimentos cooperativos (PACs), com margem de erro de 15,38\%. O número máximo de cooperados, com base na amostra, foi de 8.000 e o mínimo, de 405 associados. Nas sedes das CECM-MG trabalham, em média, 13 funcionários, e nos PACs, 5,3 (Tabela 1). 
Tabela 1 - Características das CECM-MG em 2004

\begin{tabular}{lllll}
\hline Variável & Média & Margem de Erro & \multicolumn{2}{c}{ Intervalo de confiança } \\
\hline Tempo de existência (anos) & 16 & 3,44 & 12,56 & 19,44 \\
\hline $\mathrm{N}^{\circ}$ de funcionários na sede & 13 & 2,83 & 10,57 & 15,83 \\
\hline $\mathrm{N}^{\circ}$ de funcionários nos PACs & 5,3 & 2,14 & 3,16 & 7,44 \\
\hline
\end{tabular}

Fonte: Dados da pesquisa.

Com relação à estrutura gerencial, pode-se verificar que $43 \%$ das cooperativas possuem na estrutura hierárquica o cargo de gerente-geral, com margem de erro dessa variável de 15,38 pontos porcentuais para mais ou para menos. Esses gerentes possuem, em média, 17 anos de estudo, com margem de erro de 1,7 ano, indicando que possuem curso superior. A remuneração mínima desses gerentes é de $\mathrm{R} \$ 1.500,00$ e a máxima, de $\mathrm{R} \$ 4.549,00$. A média do salário encontrada foi de $\mathrm{R} \$ 2.831,92$ e a margem de erro, de $\mathrm{R} \$ 659,63$, ou seja, a média do salário dos gerentes das CECM-MG variava de $\mathrm{R} \$ 2.172,29$ a $\mathrm{R} \$ 3.491,55$.

Levando em consideração o tempo que os diretores permaneciam na administração das CECM- $\mathrm{MG}^{4}$, contando inclusive com o revezamento de cargos, verificou-se que, em média, os diretores-presidentes permaneciam no cargo 7,45 anos (Tabela 2), enquanto o diretor " 2 " permanecia 5,95 anos e o diretor "3", 4,19 anos.

4 Conforme a Lei 5.764/71, os mandatos da diretoria devem ter duração de um a quatro anos. 
Tabela 2 - Anos de permanência dos diretores na administração das CECM-MG, contando, inclusive, com revezamento entre os cargos de direção, em 2004

\begin{tabular}{llll}
\hline Anos no cargo & Diretor-Presidente & Diretor 2 & Diretor 3 \\
\hline Média & 7,45 & 5,95 & 4,19 \\
\hline Desvio-padrão & 5,45 & 4,14 & 3,27 \\
\hline Mediana & 5,5 & 5 & 3 \\
\hline Máximo & 23 & 17 & 15 \\
\hline Mínimo & 2 & 1 & 1 \\
\hline Margem de erro & 1,74 & 1,36 & 1,07 \\
\hline
\end{tabular}

Fonte: Dados da pesquisa.

Por meio da Tabela 2, pode-se notar, com base no tempo máximo de permanência no cargo, que ele variou de 15 a 23 anos, ou seja, havia permanência de um mesmo membro no poder das cooperativas por períodos demasiadamente longos. Têm-se, nesse contexto, dois pontos de vista. Por um lado, Ferreira (2005) apontou que o tempo de permanência no cargo, medido pelos anos em que o diretor se encontrava à frente da organização, apresenta os efeitos da curva de aprendizagem sobre gestão da cooperativa, e, à medida que os gestores incorporavam o conhecimento com tempo, utilizavam com maior eficiência os recursos da cooperativa. Por outro lado, para Antonialli (2000), a renovação da diretoria da cooperativa poderia ser benéfica, visto que permitia a renovação de diretores e a geração de novas idéias.

3.2. Serviços e taxas cobradas dos associados pelas cooperativas de crédito mútuo do Estado de Minas Gerais

Verificou-se que, em média, $61 \%$ dos cooperados solicitaram empréstimos e, ou, financiamentos às suas respectivas cooperativas em 2004, com erro de amostragem de 10 pontos porcentuais para mais ou para menos.

Ao avaliar os tipos de serviços que são cobrados dos associados das CECM-MG, verifica-se, na Tabela 3, que $86 \%$ destas ofereciam empréstimos pessoais. Já a categoria de desconto de cheques era 
disponibilizada por $52 \%$ dessas cooperativas. Os serviços de crédito aos cooperados, na forma de empréstimo, destinados à aquisição de materiais e equipamentos e pagamentos de impostos, eram oferecidos por apenas $19 \%$, e o serviço de cheque especial, por 38\% das CECM-MG.

Além das finalidades de empréstimos mencionadas na Tabela 3, ao ser solicitado ao responsável pelo preenchimento do questionário que informasse quais outros tipos de empréstimo a cooperativa concedia aos associados, foram citados os seguintes: capital de giro, nota promissória, descontos recebíveis (caução), parcelamento de convênio e capital. De modo geral, essa categoria era oferecida por $25 \%$ das cooperativas de economia e crédito mútuo do Estado de Minas Gerais.

Tabela 3 - Tipos de empréstimos oferecidos aos cooperados e percentual das CECM-MG que ofereciam o serviço

\begin{tabular}{lcccc}
\hline \multicolumn{1}{c}{ Tipo de empréstimo } & $\begin{array}{c}\text { \% de cooperativas que } \\
\text { ofereciam o empréstimo }\end{array}$ & $\begin{array}{c}\text { Margem } \\
\text { de erro }\end{array}$ & \multicolumn{2}{c}{$\begin{array}{c}\text { Intervalo de } \\
\text { confiança }\end{array}$} \\
\hline Pessoal & $86 \%$ & $10,94 \%$ & $75,06 \%$ & $96,94 \%$ \\
\hline $\begin{array}{l}\text { Desconto de } \\
\text { Cheques/duplicatas }\end{array}$ & $52 \%$ & $16,38 \%$ & $35,62 \%$ & $68,38 \%$ \\
\hline Pagamento de impostos & $19 \%$ & $12,88 \%$ & $6,12 \%$ & $31,88 \%$ \\
\hline $\begin{array}{l}\text { Aquisição de } \\
\text { Materiais/equipamentos }\end{array}$ & $19 \%$ & $12,88 \%$ & $6,12 \%$ & $31,88 \%$ \\
\hline Cheque especial & $38 \%$ & $15,93 \%$ & $22,07 \%$ & $53,93 \%$ \\
\hline Outros & $25 \%$ & $14,62 \%$ & $10,38 \%$ & $39,62 \%$ \\
\hline
\end{tabular}

Fonte: Dados da pesquisa.

Nota-se que a maior parte das CECM-MG cumpria uma das principais competências desse ramo do cooperativismo, qual seja a de atender a demanda de crédito por parte do cooperado. No entanto, é importante notar que a menor parte das cooperativas efetuava recebimento de impostos, atividade capaz de gerar a entrada de recursos para a cooperativa via pagamento das concessionárias de serviços públicos. De maneira geral, o recolhimento de impostos não acarretaria ônus para a cooperativa, partindo do princípio de que os funcionários responsáveis pelo serviço de "caixa" poderiam receber os impostos, sem sobrecarga de atividades. 
Com relação às taxas cobradas pelas CECM-MG, pode-se notar que o mínimo para empréstimo pessoal era de $1,79 \%{ }^{5}$ ao mês. A cooperativa constituída em 1988 possuía 1.606 associados e tinha 17 funcionários, enquanto a que apresentava a maior taxa para empréstimo pessoal, na ordem de até $6,5 \%{ }^{6}$ ao mês, constituída em 1998, possuía 405 cooperados e tinha sete funcionários. Essas características demonstram que o tempo de atividade influencia a questão da experiência em gestão financeira e o aumento do capital social, entre outros fatores que influem na condição de praticar menores taxas de juros (Tabela 4).

Se comparada com a taxa de empréstimo pessoal dos bancos, que foi, em média, de 5,14\% ao mês (PROCON-SP (A) 2006), utilizando o mês de setembro de 2004 como uma proxy, pode-se afirmar que $95,7 \%$ das cooperativas praticavam taxa para empréstimo pessoal inferior à da média do mercado dos bancos. No entanto, apenas uma apresentou a taxa máxima de 6,5\% ao mês, no período de maio a junho de 2004, percentual superior ao da média dos bancos. Essa observação isolada não reflete a realidade da maioria das CECM-MG.

Tabela 4 - Taxas mínimas e máximas de empréstimos oferecidos aos cooperados das CECM-MG que ofereciam o serviço

\begin{tabular}{lcc}
\hline Tipo de empréstimo & Taxa mínima & Taxa máxima \\
\hline Pessoal & $1,79 \%$ & $6,50 \%$ \\
\hline Desconto de cheques/duplicatas & $1,90 \%$ & $4,59 \%$ \\
\hline Pagamento de impostos & $2,00 \%$ & $3,00 \%$ \\
\hline Aquisição de materiais/equipamentos & $2,00 \%$ & $3,44 \%$ \\
\hline Cheque especial & $2,99 \%$ & $6,99 \%$ \\
\hline
\end{tabular}

Fonte: Dados da pesquisa.

Para desconto de cheques/duplicatas, a menor taxa informada foi de $1,90 \%{ }^{7}$ ao mês, na mesma cooperativa citada anteriormente, que oferecia a menor taxa de empréstimo pessoal, enquanto a maior taxa, de $4,59 \%$ ao mês, foi de uma cooperativa fundada em 1997 que possuía 2.615

\footnotetext{
Nesta cooperativa, a taxa máxima para o empréstimo pessoal era de $3,0 \%$ ao mês.

Nesta cooperativa, a taxa mínima para o empréstimo pessoal era de 4,5\% ao mês.

Nesta cooperativa, a taxa máxima para desconto de cheques/duplicatas era de 2,4\% ao mês.

8 Nesta cooperativa, a taxa mínima para desconto de cheques/duplicatas era de 2,99\% ao mês.
} 
cooperados e 28 funcionários. As outras modalidades de empréstimo para pagamento de impostos e para aquisição de materiais/equipamentos apresentavam taxa mínima de $2 \%$ ao mês e máxima de $3 \%$ e $3,44 \%$, respectivamente.

As taxas para cheque especial oscilaram entre 2,99\% e 6,99\%, fato verificado em uma única cooperativa, que foi constituída em 1996 e possuía 3.722 cooperados e 23 funcionários. Nesse caso, é pertinente afirmar que a diferença de taxa de um associado para outro, provavelmente, era decorrente da movimentação do cooperado com a cooperativa, assim como do seu nível de fidelidade a ela, entre outros fatores. A tarifa de $6,99 \%$ para cheque especial era utilizada, unicamente, pela mesma cooperativa que praticava a maior taxa para o desconto de cheques/ duplicatas $(4,59 \%)$.

Se comparada com a taxa média dos bancos em setembro de 2004, que foi de 7,99\% ao mês (PROCON-SP (A) 2006), todas as cooperativas de crédito mútuo do Estado de Minas Gerais cobravam taxa para o cheque especial inferior à do sistema bancário.

O seguro prestamista, que garante o pagamento de empréstimos e financiamentos em casos de morte ou invalidez permanente total por acidente, era cobrado por 59\% das CECM-MG, com margem de erro de $15,68 \%$ para mais ou para menos; a menor taxa praticada era de $0,05 \%$ e a maior, de $1,00 \%$ do valor tomado emprestado.

As taxas de cadastro eram cobradas por $33 \%$ das cooperativas, com margem de erro de $15,46 \%$ para mais ou para menos. Outras taxas cobradas citadas foram: custódia de cheque, borderô, alienação e integralização mínima mensal, sendo esta categoria praticada pelo mesmo percentual de cooperativas que cobravam taxas de cadastro.

Com relação aos tipos de financiamento, verificou-se que $24 \%$ das cooperativas de crédito mútuo em Minas Gerais ofereciam financiamento para veículos, e as taxas praticadas oscilavam entre $1,98 \%$ e $2,9 \%$ ao mês (Tabelas 5 e 6). 
Tabela 5 - Tipos de financiamento oferecidos aos cooperados e percentual das CECM- MG que ofereciam o serviço

\begin{tabular}{lcccc}
\hline Tipo de financiamento & $\begin{array}{c}\text { \% de cooperativas } \\
\text { que ofereciam } \\
\text { o financiamento }\end{array}$ & $\begin{array}{c}\text { Margem } \\
\text { de erro }\end{array}$ & \multicolumn{2}{c}{$\begin{array}{c}\text { Intervalo } \\
\text { de confiança }\end{array}$} \\
\hline Veículos & $24 \%$ & $13,97 \%$ & $10,03 \%$ & $37,97 \%$ \\
\hline $\begin{array}{l}\text { Materiais, máquinas e } \\
\text { equipamentos }\end{array}$ & $19 \%$ & $12,88 \%$ & $6,12 \%$ & $31,88 \%$ \\
\hline Impostos e taxas & $5 \%$ & $7,36 \%$ & $-2,36 \%$ & $12,36 \%$ \\
\hline Outros & $25 \%$ & $14,62 \%$ & $10,38 \%$ & $39,62 \%$ \\
\hline
\end{tabular}

Fonte: Dados da pesquisa.

Tabela 6 - Taxas mínimas e máximas dos financiamentos oferecidos aos cooperados das CECM-MG que ofereciam o serviço

\begin{tabular}{lcc}
\hline \multicolumn{1}{c}{ Tipo de financiamento } & Taxa mínima & Taxa máxima \\
\hline Veículos & $1,98 \%$ & $2,9 \%$ \\
\hline Materiais, máquinas e equipamentos & $1,99 \%$ & $3,44 \%$ \\
\hline Impostos e taxas & $\mathrm{Nd}$ & $\mathrm{Nd}$ \\
\hline
\end{tabular}

Fonte: Dados da pesquisa.

Os financiamentos para materiais, máquinas e equipamentos eram disponibilizados por $19 \%$ das CECM-MG, e as taxas para este tipo de financiamento oscilavam entre $1,99 \%$ e $3,44 \%$ ao mês (Tabelas 5 e 6 ). $\mathrm{Na}$ modalidade Outros, da Tabela 5, o principal tipo de financiamento citado foi a antecipação do $13^{\circ}$ salário. As outras modalidades citadas foram: desconto de duplicatas/cheques e cheque especial, que foram averiguadas em outra questão específica do instrumento de coleta de dados.

Pode-se constatar o percentual das cooperativas que, além dos tipos de empréstimos e financiamentos mencionados anteriormente, ofereciam os seguintes serviços: convênios (55\%), seguros (23\%), recebimento de contas $(41 \%)$, recebimento de impostos (18\%), cartão de crédito/débito $(23 \%)$, aplicações $(29 \%)$ e outras modalidades: consultoria aos associados, terminal de auto-atendimento e débito automático (57\%). 
Além dessas taxas, as CECM-MG cobravam, em média, $\mathrm{R} \$ 3,06$ (podendo oscilar entre $\mathrm{R} \$ 2,23$ e $\mathrm{R} \$ 3,89$, conforme as margens de erro) para o segundo talão ao mês, com 20 folhas; $\mathrm{R} \$ 5,05$ para o DOC " $\mathrm{C}$ " DEC e TED; e R \$0,46, R \$ 5,94 e R\$13,00, respectivamente para o extrato eletrônico, cadastro de pessoa física e cadastro de pessoa jurídica (Tabela 7).

Tabela 7 - Outras taxas cobradas dos cooperados CECM-MG

\begin{tabular}{lcccc}
\hline \multicolumn{1}{c}{ Outras taxas cobradas } & $\begin{array}{c}\text { Valor médio } \\
\text { das taxas }\end{array}$ & $\begin{array}{c}\text { Margem } \\
\text { de erro }\end{array}$ & \multicolumn{2}{c}{$\begin{array}{c}\text { Intervalo } \\
\text { de confiança }\end{array}$} \\
\hline Talão 20 folhas $-2^{\circ}$ talão do mês & $\mathrm{R} \$ 3,06$ & $\mathrm{R} \$ 0,83$ & $\mathrm{R} \$ 2,23$ & $\mathrm{R} \$ 3,89$ \\
\hline Cheque especial/empresarial & $\mathrm{Nd}$ & - & - & - \\
\hline DOC “C “DEC e TED & $\mathrm{R} \$ 5,05$ & $\mathrm{R} \$ 1,08$ & $\mathrm{R} \$ 3,97$ & $\mathrm{R} \$ 6,13$ \\
\hline Extrato eletrônico & $\mathrm{R} \$ 0,46$ & $\mathrm{R} \$ 0,26$ & $\mathrm{R} \$ 0,20$ & $\mathrm{R} \$ 0,72$ \\
\hline Cadastro pessoa física & $\mathrm{R} \$ 5,94$ & $\mathrm{R} \$ 2,57$ & $\mathrm{R} \$ 3,37$ & $\mathrm{R} \$ 8,51$ \\
\hline Cadastro pessoa jurídica & $\mathrm{R} \$ 13,00$ & $\mathrm{R} \$ 7,77$ & $\mathrm{R} \$ 5,23$ & $\mathrm{R} \$ 20,77$ \\
\hline
\end{tabular}

Fonte: Dados da pesquisa.

Ao comparar os dados das cooperativas com as taxas dos bancos, utilizando o mês de setembro de 2004 como uma proxy, pode-se afirmar que nas cooperativas não era cobrado o primeiro talão de cheques ao mês, enquanto nos bancos, onde este serviço era cobrado, as taxas variavam de $\mathrm{R} \$ 4,60$ a $\mathrm{R} \$ 7,70$. A taxa do segundo talão ao mês, nas cooperativas, tinha o valor médio de $\mathrm{R} \$ 3,06$, enquanto no sistema bancário a taxa cobrada era superior, de $\mathrm{R} \$ 6,00$ a $\mathrm{R} \$ 15,00$ (Tabelas 7 e 8). 
Tabela 8 - Taxas cobradas pelos bancos, em setembro de 2004

\begin{tabular}{lrrr}
\hline \multicolumn{1}{c}{ Taxas cobradas pelos bancos } & Menor tarifa & Maior tarifa & $\begin{array}{c}\text { Diferença } \\
(\%)\end{array}$ \\
\hline Talão de cheques - 20 fls. $1^{\circ}$ no mês & $\mathrm{R} \$ 4,60$ & $\mathrm{R} \$ 7,70$ & $67 \%$ \\
\hline Talão de cheques - 20 fls. $2^{\circ}$ no mês & $\mathrm{R} \$ 6,00$ & $\mathrm{R} \$ 15,00$ & $150 \%$ \\
\hline DOC "C" & $\mathrm{R} \$ 10,00$ & $\mathrm{R} \$ 12,00$ & $20 \%$ \\
\hline DOC "D" (transferência entre c/c do mesmo correntista) & $\mathrm{R} \$ 10,00$ & $\mathrm{R} \$ 15,00$ & $50 \%$ \\
\hline Extrato eletrônico no terminal (2 ${ }^{\circ}$ no prazo de 7 dias) & $\mathrm{R} \$ 0,90$ & $\mathrm{R} \$ 1,30$ & $44 \%$ \\
\hline Cadastro na abertura da conta & $\mathrm{R} \$ 13,50$ & $\mathrm{R} \$ 18,00$ & $33 \%$ \\
\hline Renovação do cadastro - periodicidade (valor anual) & $\mathrm{R} \$ 13,50$ & $\mathrm{R} \$ 36,00$ & $167 \%$ \\
\hline
\end{tabular}

Fonte: PROCON-SP(B).

A taxa sobre os serviços de DOC, nas CECM-MG, era aproximadamente a metade do valor cobrado pelos bancos. Pelo extrato eletrônico nas CECM-MG cobrava-se em média $R \$ 0,46$, enquanto nos bancos esta taxa oscilava entre $R \$ 0,90$ e $R \$ 1,30$. Com relação às taxas de cadastro, pode-se verificar que para pessoas físicas as cooperativas cobravam em torno de $\mathrm{R} \$ 5,94$ e, para pessoas jurídicas, $\mathrm{R} \$ 13,00$; já no sistema bancário, a taxa de cadastro para abertura de conta de pessoas físicas era de, no mínimo, $\mathrm{R} \$ 13,50$, além de se cobrar pela renovação de cadastro anualmente, que oscilava entre $\mathrm{R} \$ 13,50$ e $\mathrm{R} \$ 36,00$. Os dados do ProconSP (B) (2006) não discriminaram as taxas para pessoas jurídicas (Tabelas 7 e 8$)$.

De modo geral, pode-se afirmar que as cooperativas de crédito disponibilizam serviços com custos menores que os da média do mercado. A origem dos recursos das cooperativas é o capital próprio aportado pelos cooperados mais as receitas obtidas em operações; quanto mais os cooperados transacionam com a cooperativa, mais recursos ela possui para emprestar aos associados e mais baratos ficam os serviços.

Essas constatações condizem com a opinião de Pochmann (Bancred, 2006), ao afirmar que "o Brasil convive com um sistema bancário que não está adequado às suas reais necessidades, pois o perfil dos bancos brasileiros dificulta a aplicação das medidas para ampliar o microcrédito, uma atividade que também é desenvolvida por cooperativas de crédito". 


\subsection{Análise das cooperativas na concessão de crédito}

Considerando todas as CECM-MG filiadas à CECREMGE (Central das Cooperativas de Crédito Mútuo do Estado de Minas Gerais), pode-se considerar que, em média, 282 cooperados solicitaram empréstimos em março de 2004. ${ }^{9}$ Destes cooperados, uma média de 259 foi atendida. Essas informações permitem explanar que em média, no mês de março de 2004, 92\% dos cooperados das CECM-MG foram atendidos, com empréstimos, por suas respectivas cooperativas (Tabela 9).

Nesse mesmo período, pôde-se verificar que o número médio de cooperados inadimplentes foi de 58 pessoas, representando $22,34 \%$ de inadimplência (Tabela 9).

Tabela 9 - Solicitantes, atendidos e inadimplentes nas CECM-MG, em março de 2004

\begin{tabular}{llll}
\hline & Solicitantes & Atendidos & Inadimplentes \\
\hline Média & 281,94 & 259,41 & 57,96 \\
\hline Desvio-padrão & 237,70 & 217,79 & 77,15 \\
\hline Mediana & 169 & 169 & 36 \\
\hline Máximo & 700 & 650 & 279 \\
\hline Mínimo & 14 & 13 & 0 \\
\hline Margem de erro & 88,34 & 80,94 & 30,82 \\
\hline Intervalo de confiança & $(193,60 ; 370,28)$ & $(178,47 ; 340,35)$ & $(27,14 ; 88,78)$ \\
\hline
\end{tabular}

Fonte: Dados da pesquisa.

\subsection{Ponto de vista dos gestores em relação às cooperativas de crédito}

Constatou-se que a maioria dos gestores das CECM-MG possui um entendimento coerente com o real significado de uma cooperativa, visto que a seguinte definição: "cooperativa é uma associação autônoma de pessoas que se unem, voluntariamente, para satisfazer às aspirações e

\footnotetext{
Foi necessário padronizar uma data no período de levantamento dos dados, de forma que permitisse a comparação entre estes. Por esse motivo, trabalhou-se com o mês de março de 2004, período coincidente com o fato de todas as cooperativas terem recebido os questionários.
} 
necessidades econômicas, sociais e culturais comuns, por meio de uma empresa democrática de propriedade coletiva" foi aceita como correta por $83 \%$ dos respondentes, entre outros conceitos apresentados no questionário. A margem de erro desta questão é de 11,76 pontos percentuais para mais ou para menos.

Avaliou-se a percepção dos gestores quanto à livre associação das cooperativas de crédito autorizado a partir de 2003, com base na Resolução 3.106 do Banco Central do Brasil. A maioria desses gestores considerou esta alternativa positiva para as cooperativas de crédito devido a uma série de fatores, a saber: permite o aumento do número de associados com consequiente aumento do valor de capital social e possibilidade de aumento das sobras da cooperativa, que acarretará vários benefícios, como diminuição dos custos e das taxas de juros, aumento da oferta de serviços com menores taxas e rendimento sobre o capital integralizado; proporciona a inclusão social em cidades de pequeno porte, devido ao acesso a produtos e serviços financeiros pela população, que não dispõe de atendimento do sistema bancário; permite a diversificação do risco da cooperativa em função de maior volume de capital; e fomenta a criação de novos negócios para pequenos e microempreendedores, permitindo a criação de novos empregos e melhoria da qualidade de vida.

Entretanto, alguns gestores fizeram ressalvas quanto à livre associação, no sentido de que o vínculo com o associado será diferente, pois, nas cooperativas formadas com funcionários de instituições ou com membros de categorias de classe, há um perfil similar, ou seja, existe o conhecimento do grupo sobre os cooperados. Já a livre associação, segundo eles, dificultará esse maior conhecimento intergrupal, além de acreditarem que a gerência deverá ter maiores cuidados com os critérios para concessão de crédito.

Outro gestor considerou que no Brasil não se tem a cultura cooperativista amplamente difundida e, por esse motivo, ainda existe a mentalidade de "levar vantagem" via cooperativa. Assim, considera essencial que exista, inicialmente, a compreensão de que o "cooperativismo é a união de um 
grupo ou classe para o bem coletivo" e não um sistema que preza o retorno econômico-financeiro para apenas um indivíduo, para, posteriormente, permitir a livre adesão às cooperativas de crédito.

Um grupo menor de respondentes foi desfavorável à livre adesão, autorizada pela Resolução 3.106/2003, por considerar as seguintes perdas para as cooperativas de crédito: aumento do risco de inadimplência; perda da "essência" da cooperativa, que passaria a atuar como bancos e financeiras; e, no caso de cidades de maior porte, foi mencionada a possibilidade da perda de identidade com o associado e a massificação/ despersonalização do atendimento.

Todos esses pontos de vista são importantes para o sistema das cooperativas de crédito, e espera-se que a opinião dos discordantes possa despertar no próprio sistema maneiras de minimizar os possíveis problemas apontados.

\section{Conclusões}

A principal contribuição deste trabalho foi detectar as principais características das cooperativas de economia e crédito mútuo do Estado de Minas Gerais, a saber: possuíam, em média, 16 anos de existência; $43 \%$ tinham postos de atendimentos cooperativos, estrutura que permite ampliar o raio de ação das cooperativas, com vistas ao atendimento com maior comodidade para os associados; a média de tempo dos diretores na administração das cooperativas era de 7,45 anos; e a remuneração média dos gerentes era de $\mathrm{R} \$ 2.831,92$.

Constatou-se que essas cooperativas, em Minas Gerais, atendem à sua principal competência, qual seja: praticar taxas para empréstimo pessoal inferior às da média do sistema bancário, além de várias outras taxas de serviços inferiores àquelas praticadas pelos bancos. As CECM-MG atenderam a $92 \%$ das solicitações de crédito por parte do associado, e o percentual médio de inadimplência, no período do estudo, foi de $22,34 \%$. 
Nesse sentido, as cooperativas têm cumprido o seu principal papel, que é de redução da intermediação financeira nas operações de crédito. Tratase de uma operação direta de crédito entre o aplicador e o tomador, pois os associados são, ao mesmo tempo, donos e usuários das cooperativas e beneficiam-se dos rendimentos das transações financeiras que seriam destinados aos intermediários.

Importante notar que cooperativas com maior tempo de existência praticavam menores taxas de juros, resultado esse decorrente de maior experiência na gestão financeira e de uma estrutura financeira melhor consolidada, resultante do maior volume de capital social na cooperativa.

Destaca-se também que a menor parte das cooperativas prestava serviços de recolhimento de impostos e tarifas de água, luz e telefone, atividade essa capaz de gerar resultados financeiros para elas próprias, em razão dos pagamentos realizados por parte das concessionárias pelo serviço prestado, e de proporcionar maior comodidade para o cooperado, pelo fato de poder realizar esses pagamentos na cooperativa.

Por fim, observou-se que $83 \%$ dos gestores tinham percepção adequada sobre o real significado de uma cooperativa. De modo geral, tem-se uma visão positiva da livre adesão às cooperativas de crédito, apesar de alguns gestores terem sinalizado para possíveis problemas de aumento de inadimplência, perda da identidade cooperativa e massificação e despersonalização do atendimento ao cooperado, com a implementação da Resolução 3.106/2003 pelo Banco Central do Brasil.

Considera-se como limitação do presente trabalho o reduzido percentual de retorno de apenas 18,85\% dos questionários enviados, apesar da amostragem estatisticamente significativa, e a não-possibilidade, nesse momento de pesquisa, de averiguar todas as cooperativas de crédito do Brasil. Sugere-se para trabalhos futuros a averiguação do perfil das cooperativas de crédito em nível nacional, confrontando análises setoriais, com vistas a avaliar se existe ou não homogeneidade entre elas. 


\section{Referências}

ANTONIALLI, L. M. Influência da mudança de gestão nas estratégias de uma cooperativa agropecuária. Revista de Administração Contemporânea - RAC, Rio de Janeiro-RJ, v. 4, n. 1, p. 135-159, 2000.

BANCRED. Microcrédito deve estar vinculado às atividades produtivas. Mais Bancred. Ano 1, $\mathrm{n}^{\circ}$ 5, dezembro de 2004. Disponível e m : h t t p://w w w. bancredi.com.br/arquivos / Bancredi\%20Mais\%20N\%C2\%BA5.pdf. Acesso em: 29 mar. 2006.

FERREIRA, Marco Aurélio Marques. Eficiência técnica e de escala de cooperativas e sociedades de capital na indústria de laticínios do Brasil. 2005. 164 f. Tese (Doutorado em Economia Aplicada) Universidade Federal de Viçosa, Minas Gerais, 2005.

FULLY-BRESSAN, Valéria Gama. Análise de insolvência das cooperativas de crédito rural do estado de Minas Gerais. 2002. 122 f. Dissertação (Mestrado em Economia Aplicada) - Universidade Federal de Viçosa, Minas Gerais, 2002.

GIL, Antônio Carlos. Métodos e técnicas de pesquisa social. 5. ed. São Paulo: Atlas, 1999. 206p.

GONÇALVES, Rosiane Maria Lima Condicionantes do risco de liquidez em cooperativas de economia e crédito mútuo do Estado de Minas Gerais. 2006. 118 f. Dissertação (Mestrado em Economia Aplicada) “ Universidade Federal de Viçosa, Minas Gerais, 2006.

JUNQUEIRA, Rodrigo Gravia Prates. Finanças solidárias e agricultura familiar: $O$ sistema cresol de cooperativas de crédito rural. 2003. 109f. Dissertação (Mestrado em Ciência Ambiental) “ Universidade de São Paulo, São Paulo. 2003. 
LEVINE, D. M.; BERENSON, M. L.; STEPHAN, D. Estatística: teoria e aplicações. Rio de Janeiro: LTC - Livros Técnicos e Científicos Editora S.A., 2000. 811p.

ORGANIZAÇÃO DAS COOPERATIVAS BRASILEIRAS “ OCB. Ramos do cooperativismo. Disponível em: www.ocb.org.br. Acesso em: 7 nov. 2006.

PARENTE, S. Mercado financeiro e a população de baixa renda. In: SEMINÁRIO BANCO CENTRAL SOBRE MICROFINANÇAS, 2., 2003, Fortaleza. Anais... Disponível em: <http://www.bcb.gov.br/pre/ SeMicro/Trabalhos >. Acesso em: 12 jul. 2005.

PINHEIRO, M. A. H. Cooperativas de Crédito: história da evolução normativa no Brasil. Banco Central do Brasil, Brasília, 2005. Disponível em: $\quad$ http://bcb.gov.br/htms/public/microcredito/ cartilha cooperativas credito.pdf.> Acesso em: 30 mar. 2006.

PROCON-SP (A). Procon-SP divulga pesquisa de tarifas bancárias. Diferenças chegam a 369,57\%. Disponível em: < http:// www.procon.sp.gov.br/infpressassfinbancosetembro.shtml> Acesso em: 31 mar. 2006.

PROCON-SP (B). Procon-SP divulga pesquisa de tarifas bancárias. Diferenças chegam a 369,57\%. Disponível em: <http:// www.procon.sp.gov.br/infpressassfinbalancotarifas2004.shtml.> Acesso em: 31 mar. 2006.

RESOLUÇÃO 3.106. Dispõe sobre os requisitos e procedimentos para a constituição, a autorização para funcionamento e alterações estatutárias, bem como para o cancelamento da autorização para funcionamento de cooperativas de crédito. (24 de junho de 2003). Disponível em: http:// w w w 5.b c b.gov.br/ixpress/correio/correio/ DETALHAMENTOCORREIO.DML?N=103087623\&C=3106\&ASS= RESOLUCAO+3.106. Acesso em: 13 out. 2006. 
QUIROGA, M. del P. S.; FULLY-BRESSAN, V. G.; BRAGA, M. J. A avaliação financeira das cooperativas de crédito mútuo do Estado de Minas Gerais. In: CONGRESSO BRASILEIRO DE ECONOMIA E SOCIOLOGIA RURAL, 42. 2004, Cuiabá. Anais ... Cuiabá: SOBER, 2004.

SCHRÖDER, M. Cooperativas de crédito da agricultura familiar, inovações institucionais e acesso a serviços financeiros: o caso do sistema cresol, no sul do Brasil . In: CONGRESSO DA SOBER. 43., 2005. Ribeirão Preto. Anais... Ribeiro Preto, SOBER, 2005. 21p.

WOCCU - World Council of Credit Unions. Statiscal Report 2004. Disponível em: <www.woccu.org > . Acesso em: 14 fev. 2006.

\begin{abstract}
Given the relevance of the credit unions at national and world level, the objective of this work was to describe the profile of the financial cooperatives from the Brazilian state of Minas Gerais. This study is based on data collected in the period of May to June of 2004, and the sample of $18.85 \%$ of the population was selected to supply data. The results indicate that the cooperatives were, on average, 16 years old; $92 \%$ of the associates that requested loans were assisted; the delinquent loans level were of $22.34 \%$; and older cooperatives established smaller interest rates than the new ones. The managers had appropriate perception of the true meaning of a cooperative and they agreed with the cooperative principle of voluntary and open membership. In general, credit unions serve their members supplying services with smaller costs than the bank system, thus, they provide financial service to low-income people accomplishing their role in the microfinance system.
\end{abstract}

Keywords: Credit unions, microfinance, Minas Gerais. 
REVISTA DE ECONOMIA E AGRONEGÓCIO, VOL.4, $N^{\circ} 4$ 